\title{
Morphological Characterization of Three Intergeneric Hybrids Among Gloriosa superba 'Lutea', Littonia modesta, and Sandersonia aurantiaca (Colchicaceae)
}

\author{
Junji Amano, Sachiko Kuwayama, Yoko Mizuta, and Masaru Nakano' \\ Faculty of Agriculture, Niigata University, 2-8050 Ikarashi, Niigata \\ 950-2181, Japan
}

Toshinari Godo

Botanic Gardens of Toyama, 42 Kamikutsuwada, Fuchu-Machi, Toyama 939-2713, Japan

\section{Hajime Okuno} 3250-201 Fukaisawa-Machi, Naka-Ku, Sakai 599-8236, Japan

Additional index words. chromosome, colchicaceous ornamentals, Santonia 'Golden Lights'

Abstract. Three intergeneric hybrids among colchicaceous ornamentals, Gloriosa superba 'Lutea' $(2 n=2 x=22)$, Littonia modesta $(2 n=2 x=22)$, and Sandersonia aurantiaca $(2 n=$ $2 x=24)$, were subjected to morphological characterization and chromosome observation. Hybrid plants produced flowers 2 to 3 years after transplantation of ovule culturederived plantlets to the greenhouse. All the hybrid plants, $L$. modesta $\times S$. aurantiaca, L. modesta $\times$ G. superba 'Lutea', and $S$. aurantiaca $\times$ G. superba 'Lutea', showed a climbing habit like those of $L$. modesta and G. superba 'Lutea'. Plants of L. modesta $\times$ $S$. aurantiaca and $L$. modesta $\times G$. superba 'Lutea' were taller and shorter than their respective parents, whereas plant height of $S$. aurantiaca $\times G$. superba 'Lutea' was nearly intermediate between the parents. Leaves of all the hybrids had a tendril at the tip like those of $L$. modesta and G. superba 'Lutea'. Flower morphologies of all the hybrids were nearly intermediate between the parents. Flower colors of all the hybrids were similar to the seed or pollen parent. Although hybrids of $L$. modesta $\times G$. superba 'Lutea' showed low pollen fertility as assessed with acetocarmine staining, the other two kinds of hybrids had nondehiscent anthers or no fertile pollen grains. Chromosome observation in root tip cells revealed that all the hybrids had a diploid number of chromosomes: $L$. modesta $\times$ S. aurantiaca $(2 n=2 x=23)$, L. modesta $\times G$. superba 'Lutea' $(2 n=2 x=22)$, and $S$. aurantiaca $\times$ G. superba 'Lutea' $(2 n=2 x=23)$. Novel morphological characteristics of the hybrids may be valuable for future breeding of colchicaceous ornamentals.

Colchicaceae consists of 19 genera that are distributed worldwide except for South America (Vinnersten and Reeves, 2003). Several genera of this family such as Gloriosa, Littonia, and Sandersonia contain horticulturally important plants cultivated as pot or cut flowers.

Although more than a dozen species with different morphologies and ploidy levels have been described for Gloriosa, most of them are currently regarded as forms of G. superba L. (Nordenstam, 1998; Vinnersten and Reeves, 2003). G. superba is native to the tropics of Africa and Asia (Nordenstam, 1998). The plants show a climbing habit and

\footnotetext{
Received for publication 8 May 2007. Accepted for publication 1 July 2007.

This work was supported in part by the Sasakawa Scientific Research Grant from the Japan Science Society.

${ }^{1}$ To whom reprint requests should be addressed; e-mailmnakano@agr.niigata-u.ac.jp.
}

have sessile leaves with a tendril at the tip. The flowers are pendulous and yellow, red, purplish, or variously bicolored in color. The tepals are undulate and reflexed turning upward and backward. G. superba 'Lutea', a diploid cultivar with yellow flowers, was used in the present study.

Littonia consists of $\approx 8$ species that are distributed in Africa, from South Africa to Senegal and Arabia (Nordenstam, 1998). L. modesta Hook. is a climbing plant with sessile leaves and leaf tip tendrils. The plants have pendulous and campanulate flowers not opening widely. Littonia modesta with orange-yellow flowers was used in the present study.

Sandersonia aurantiaca Hook. is a monotypic species native to Southern Africa (Nordenstam, 1998). The plants show a simple erect habit and have sessile leaves usually with a tendril at the tip. The flowers are pendulous, bell-shaped, and orange-yellow in color. Sandersonia aurantiaca with no leaf apical tendrils was used in the present study.
Broad hybridization has been performed for widening the variability in horticultural traits of colchicaceous ornamentals mentioned previously. Santonia 'Golden Light', an intergeneric hybrid cultivar of $S$. aurantiaca $\times$ L. modesta, has already been developed through ovule culture (Clark et al., 2005; Eason et al., 2001; Morgan et al., 2001, 2003). This cultivar has long stems and leaves with an apical tendril similar to L. modesta, but leaf and flower morphologies are intermediate between the parents. Flower color of Santonia 'Golden Light' is orange like both parents, although flowers often redden under cooler environments (Clark et al., 2005; Eason et al., 2001; Morgan et al., 2003).

We also examined the production of intra- and intergeneric hybrids in colchicaceous ornamentals through ovule culture (Kuwayama et al., 2005b; Nakamura et al., 2005). To date, over 100 independent ovule culture-derived plants in our study have been confirmed to be hybrids by flow cytometry or random-amplified polymorphic DNA analyses (Amano et al., 2007). Some hybrid plants, including those of $L$. modesta $\times S$. aurantiaca, L. modesta $\times$ G. superba L. 'Lutea', and $S$. aurantiaca $\times G$. superba 'Lutea', produced flowers 2 to 3 years after cultivation in the greenhouse. In the present study, we carried out morphological characterization, analysis of pollen fertility, and chromosome observation in these three intergeneric hybrids for evaluating the validity of intergeneric hybridization in the improvement programs of colchicaceous ornamentals. We demonstrated for the first time characteristics of intergeneric hybrids of $L$. modesta $\times G$. superba 'Lutea' and $S$. aurantiaca $\times$ G. superba 'Lutea'.

\section{Materials and Methods}

The parents for intergeneric crosses (Kuwayama et al., 2005b), G. superba 'Lutea' (Gsu; $2 n=2 x=22)$, L. modesta $($ Lit; $2 n=2 x=$ 22 ), and $S$. aurantiaca (Sau; $2 n=2 x=24$ ), were planted in pots containing a 3:2:1 mixture of loam soil, leaf mold, and compost. They were cultivated in the greenhouse without heating. The temperatures were 5 to $20^{\circ} \mathrm{C}$ night $/ 10$ to $35^{\circ} \mathrm{C}$ day, respectively, depending on the season and weather. Each tuber was divided into two to three pieces each with one bud. Then every year, the pieces were transplanted to new pots from late March to early April.

Ovule culture-derived plantlets of the three kinds of intergeneric hybrids (Amano et al., 2007; Kuwayama et al., 2005b) were cultured on half-strength MS (Murashige and Skoog, 1962) medium. Growth regulators were lacking, but with $30 \mathrm{~g} \cdot \mathrm{L}^{-1}$ sucrose and $0.2 \%$ gellan gum added. Plantlets were grown under a 16-h photoperiod with fluorescent light $\left(50 \mu \mathrm{mol} \cdot \mathrm{m}^{-2} \cdot \mathrm{s}^{-1}\right)$. Well-growing plantlets with a small tuber were acclimatized, transplanted to pots, and cultivated under the same conditions as the parental plants. After 2 years of cultivation, tubers of the hybrids were divided and transplanted to new pots as were the parental plants. 
Three years after cultivation of the hybrid plants in the greenhouse, morphological characterization, analysis of pollen fertility, and chromosome observation were carried out in the hybrids and parents. Three plants were investigated for each parental species. Three plants derived from independent ovules for each of Lit $\times$ Sau and Lit $\times$ Gsu and one plant for Sau $\times$ Gsu were investigated. Plant height at the end of the flowering stage, mean leaf length and width of three leaves below the first flower for each plant, number of flowers per plant, mean flower length and diameter of the first three flowers for each plant were measured. Flower color was investigated visually with the aid of the JHS Color Chart (Japan Horticultural Plant Standard Color Chart, 1984) and expressed using Inter-Society Color Council, National Bureau of Standard color name as well as JHS Color Chart number according to Kuwayama et al. (2005a).

Pollen fertility was evaluated by staining pollen grains with $1 \%(\mathrm{w} / \mathrm{v})$ acetocarmine and described as the percentage of pollen grains with deeply stained cytoplasm (Nakano and Mii, 1993). For chromosome observation, vigorously growing root tips were excised from greenhouse-grown plants, pretreated with $0.0005 \%(\mathrm{w} / \mathrm{v})$ amiprophosmethyl for $3 \mathrm{~h}$ at room temperature, and fixed in 3:1 (v/v) absolute ethanol: acetic acid for at least $12 \mathrm{~h}$. Chromosome observation in root tip cells was carried out according to Fukui (1996).

\section{Results}

Lit $\times$ Sau. Three independent hybrid plantlets had been obtained by ovule culture (Amano et al., 2007). Each was transplanted successfully to the greenhouse. After 2 years of cultivation, tubers of the hybrids weighed $\approx 3.2 \mathrm{~g}$ on average. One hybrid plant grew well and produced flowers in the second year. Each hybrid plant produced flowers in mid-
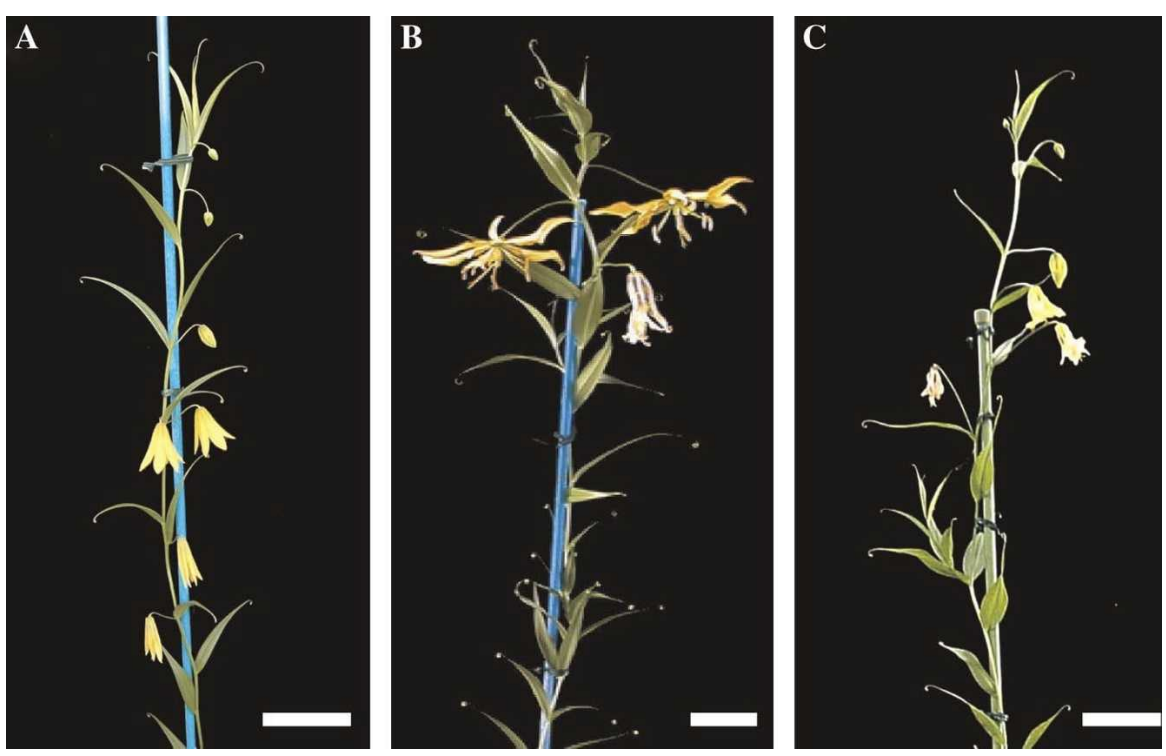

Fig. 1. Flowering plants: (A) Littonia modesta $($ Lit $) \times$ Sandersonia aurantiaca $($ Sau $) ;($ B) Lit $\times$ Gloriosa superba 'Lutea' (Gsu); (C) Sau $\times$ Gsu. Bars $=5 \mathrm{~cm}$.

June in the third year, whereas Lit and Sau did in mid-June and early June, respectively. There were no apparent morphological differences among the three independent hybrid plants. Hybrid plants at the flowering stage showed a climbing habit similar to Lit (Fig. 1A), but they were taller than both parents (Table 1). The hybrids had sessile leaves with a similar size to Sau. Hybrid leaves had a tendril at the tip like those of Lit (Table 1; Fig. 2A). Number of flowers per plant of the hybrids was similar to Sau (Table 1). Hybrid flowers were pendulous and had a nearly intermediate morphology between the parents, but they were distinguishable from parental flowers (Fig. 3A). Tepals of hybrid flowers were fused for basal half of their length, whereas those of Lit and Sau were entirely separate and fused, respectively. The tip of tepals of hybrid flowers slightly curved outwardly. Flower color of the hybrids was vivid orange (JHS 1605) like those of the flower base of both parents when checked visually using the JSH Color Chart (Table 1; Fig. 3A). All the three hybrid plants had yellow, nondehiscent anthers, which turned brown in senescent flowers. Chromosome observation in root tip cells indicated that all the three hybrid plants had a diploid number of chromosomes $(2 n=2 x=23)$ (data not shown).

Lit $\times G s u$. Three independent hybrid plantlets had been obtained (Amano et al., 2007). Each was successfully transplanted to the greenhouse. After 2 years of cultivation, hybrid tubers weighed $\approx 5.7 \mathrm{~g}$ on average. One hybrid plant produced flowers in the second year. Each hybrid plant produced flowers in late August in the third year, whereas Lit and Gsu did in mid-June and

Table 1. Comparison of morphological characteristics among intergeneric hybrids and their parents in Colchicaceae. ${ }^{\mathrm{z}}$

\begin{tabular}{|c|c|c|c|c|c|c|c|c|c|c|}
\hline \multirow[b]{2}{*}{ Hybrids or parents } & \multirow[b]{2}{*}{$\begin{array}{l}\text { Plant } \\
\text { ht }(\mathrm{cm})\end{array}$} & \multicolumn{2}{|c|}{ Leaf $^{\mathrm{y}}$} & \multirow{2}{*}{$\begin{array}{c}\text { No. of } \\
\text { flowers } \\
\text { per plant }\end{array}$} & \multicolumn{2}{|c|}{ Flower $^{\mathrm{x}}$} & \multicolumn{2}{|c|}{ Flower color $^{\mathrm{w}}$} & \multirow[b]{2}{*}{$\begin{array}{l}\text { Chromosome } \\
\text { number }(2 n)\end{array}$} & \multirow{2}{*}{$\begin{array}{c}\text { Pollen } \\
\text { fertility } \\
(\%)\end{array}$} \\
\hline & & $\begin{array}{l}\text { Length } \\
(\mathrm{cm})\end{array}$ & $\begin{array}{l}\text { Width } \\
(\mathrm{cm})\end{array}$ & & $\begin{array}{l}\text { Length } \\
(\mathrm{cm})\end{array}$ & $\begin{array}{c}\text { Diam. } \\
(\mathrm{cm})\end{array}$ & $\begin{array}{l}\text { JHS Color } \\
\text { Chart no. }\end{array}$ & $\begin{array}{l}\text { ISCC-NBS } \\
\text { color name }\end{array}$ & & \\
\hline \multicolumn{11}{|l|}{ Parents } \\
\hline Gloriosa superba & & & & & & & & & & \\
\hline $\begin{array}{l}\text { 'Lutea' (Gsu) } \\
\text { Littonia }\end{array}$ & $133.4 \pm 5.5$ & $10.4 \pm 0.8$ & $2.1 \pm 0.1$ & $7.3 \pm 0.3$ & $8.6 \pm 0.7$ & $9.6 \pm 0.4$ & 2505 & Bright yellow & $2 x=22$ & 94.8 \\
\hline modesta (Lit) & $143.7 \pm 14.7$ & $11.7 \pm 6.8$ & $0.9 \pm 0.1$ & $2.7 \pm 0.3$ & $3.4 \pm 0.3$ & $3.5 \pm 0.3$ & $\begin{array}{l}1605 \\
2205\end{array}$ & $\begin{array}{l}\text { Vivid orange } \\
\text { Vivid yellow }\end{array}$ & $2 x=22$ & 88.7 \\
\hline $\begin{array}{l}\text { Sandersonia } \\
\quad \text { aurantiaca }(\mathrm{Sau})\end{array}$ & $55.1 \pm 6.8$ & $6.5 \pm 0.8$ & $1.2 \pm 0.1$ & $6.0 \pm 0.6$ & $2.5 \pm 0.1$ & $2.5 \pm 0.1$ & $\begin{array}{l}1605 \\
2205\end{array}$ & $\begin{array}{l}\text { Vivid orange } \\
\text { Vivid yellow }\end{array}$ & $2 x=24$ & 95.4 \\
\hline Intergeneric hybrids & & & & & & & & & & \\
\hline Lit $\times$ Sau & $157.9 \pm 8.9$ & $6.0 \pm 0.4$ & $1.0 \pm 0.1$ & $6.0 \pm 1.2$ & $2.5 \pm 0.1$ & $2.7 \pm 0.2$ & 1605 & Vivid orange & $2 x=23$ & $\mathrm{ND}^{\mathrm{v}}$ \\
\hline Lit $\times$ Gsu & $89.5 \pm 9.8$ & $8.0 \pm 0.8$ & $0.9 \pm 0.1$ & $6.7 \pm 1.5$ & $3.3 \pm 0.1$ & $10.4 \pm 0.6$ & 2505 & Bright yellow & $2 x=22$ & 2.4 \\
\hline $\mathrm{Sau} \times \mathrm{Gsu}$ & 78.0 & $7.9 \pm 0.3$ & $1.5 \pm 0.1$ & 5.0 & $2.7 \pm 0.2$ & $2.3 \pm 0.2$ & 2511 & Light yellow & $2 x=23$ & 0 \\
\hline
\end{tabular}

${ }^{\mathrm{z}}$ Values except for those of flower color and chromosome number represent the mean \pm SE of three plants for each parent and the mean \pm SE of three plants derived from independent ovules for L. modesta $\times$ S. aurantiaca and L. modesta $\times$ G. superba 'Lutea'. One plant was investigated for S. aurantiaca $\times$ G. superba 'Lutea'. ${ }^{y}$ Three leaves below the first flower were investigated for each plant. For $S$. aurantiaca $\times$ G. superba 'Lutea', values represent the mean \pm SE of the three leaves. xThe first three flowers were investigated for each plant. For $S$. aurantiaca $\times$ G. superba 'Lutea', values represent the mean \pm SE of the three flowers.

${ }^{\text {w} F l o w e r ~ c o l o r ~ w a s ~ c h e c k e d ~ v i s u a l l y ~ w i t h ~ a n ~ a i d ~ o f ~ t h e ~ J H S ~ C o l o r ~ C h a r t ~[J a p a n ~ H o r t i c u l t u r a l ~ P l a n t ~ S t a n d a r d ~ C o l o r ~ C h a r t ~(1984)] . ~ F o r ~ L . ~ m o d e s t a ~ a n d ~ S . ~ a u r a n t i a c a, ~}$ flower colors were gradated from vivid orange (flower base; upper line) to vivid yellow (flower tip; lower line).

Not determined as a result of nondehiscent anthers.

ISCC-NBS = Inter-Society Color Council, National Bureau of Standard. 

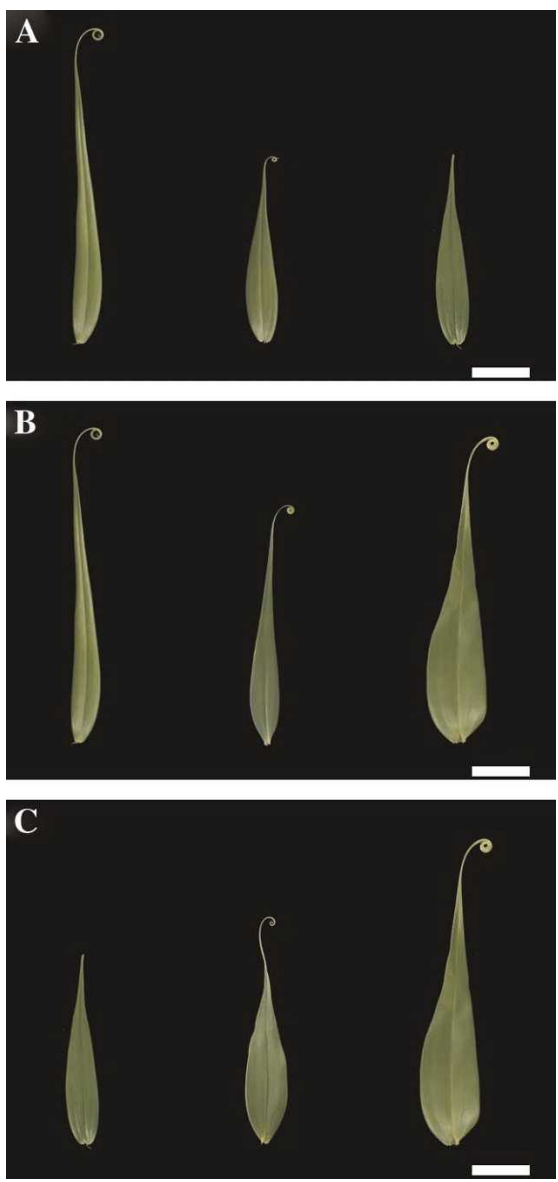

Fig. 2. Leaves: (A) Littonia modesta (Lit; left), Lit $\times$ Sandersonia aurantiaca (Sau; middle), and Sau (right). (B) Lit (left), Lit $\times$ Gloriosa superba 'Lutea' (Gsu; middle), and Gsu (right). (C) Sau (left), Sau $\times$ Gsu (middle), and Gsu (right). $\mathrm{Bar}=2 \mathrm{~cm}$.

early July, respectively. No apparent morphological differences were observed among the three independent hybrid plants. Although hybrid plants showed a climbing habit like both parents (Fig. 1B), they were much shorter than both parents (Table 1). Hybrid plants had a few vegetative shoots below the first flower like Gsu, whereas plants of Lit produced no vegetative shoots. The hybrids had leaves with a similar width to Lit but a shorter length than both parents (Table 1; Fig. 2B). Hybrid leaves were sessile and had a tendril at the tip like those of both parents (Fig. 2B). Number of flowers per plant of the hybrids was similar to Gsu (Table 1). Hybrid flowers were pendulous and had nearly horizontally expanded tepals, which were apparently distinguishable from parental flowers (Fig. 3B). Flower length of the hybrids was similar to Lit, whereas flower diameter of the hybrids was similar to Gsu (Table 1). Tepals of hybrid flowers were undulate and entirely separate like those of Gsu, but the tip of hybrid tepals was only slightly reflexed. Styles of Gsu flowers were bent to nearly right-angled from the base, whereas those of Lit were erect. Flowers of the hybrids had a slightly bent style. Flower color of the hybrids was bright yellow (JHS
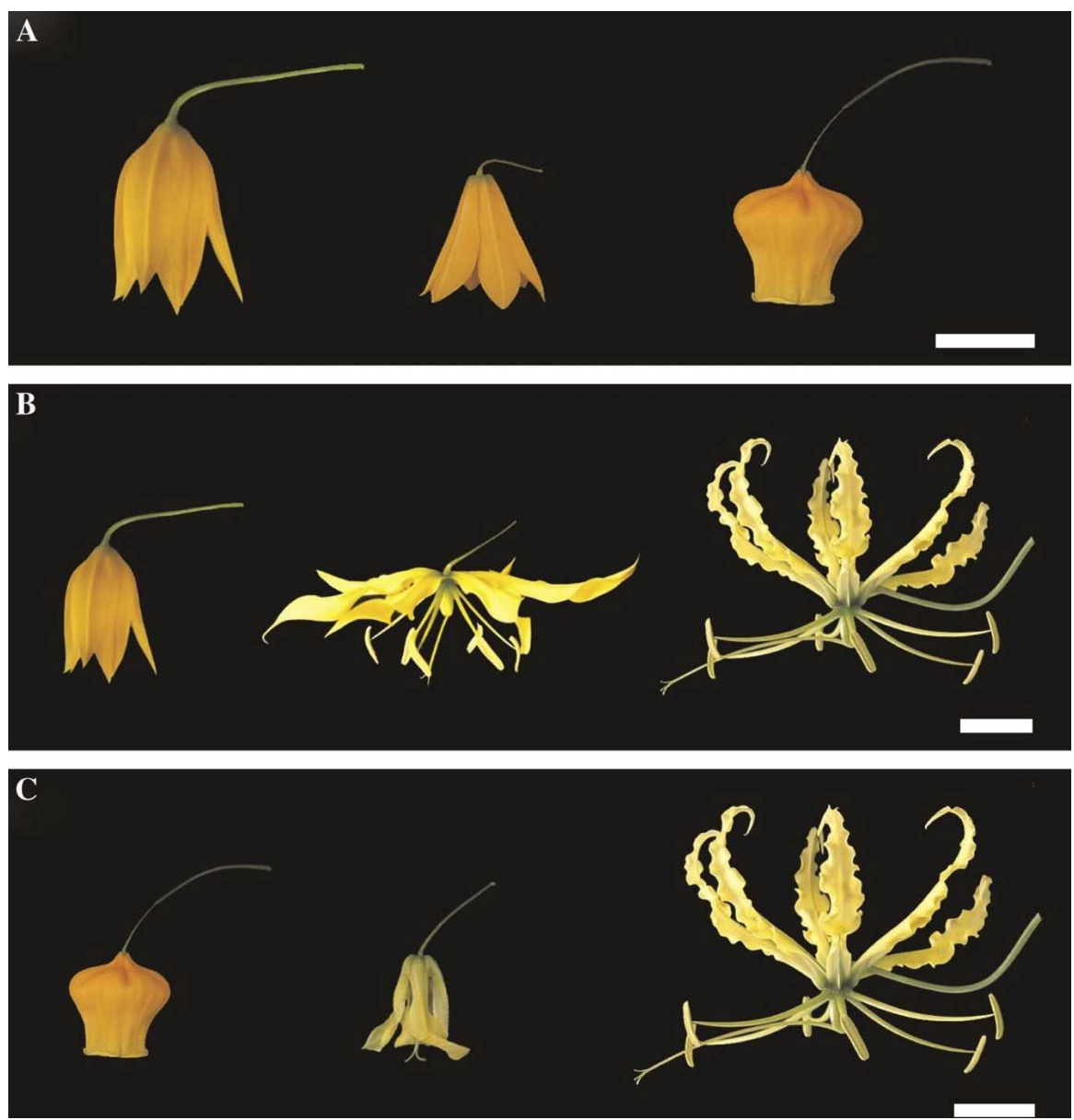

Fig. 3. Flowers: (A) Littonia modesta (Lit; left), Lit $\times$ Sandersonia aurantiaca (Sau; middle), and Sau (right). (B) Lit (left), Lit $\times$ Gloriosa superba 'Lutea' (Gsu; middle), and Gsu (right). (C) Sau (left), Sau $\times$ Gsu (middle), and Gsu (right). Bar $=2 \mathrm{~cm}$.

2505) like those of Gsu (Table 1; Fig. 3B). Although all the hybrid plants had partly dehiscent anthers, their pollen fertility was only $2.4 \%$ as assessed with acetocarmine staining (Table 1). All the three hybrid plants had a diploid number of chromosomes $(2 n=$ $2 x=22)$ (data not shown).

Sau $\times$ Gsu. Six independent hybrid plantlets had been obtained (Amano et al., 2007). Among them, two diploid hybrids as shown by flow cytometry analysis were successfully transplanted to the greenhouse. After 2 years of cultivation, tubers of the two hybrids weighed $\approx 3.2 \mathrm{~g}$ on average. One hybrid plant produced flowers in mid-August in the third year, whereas Sau and Gsu did in early June and early July, respectively. The rest one hybrid has not yet produced flowers. Both hybrid plants showed a climbing habit like Gsu (Fig. 1C). The following morphological characterization and analysis of pollen fertility were carried out by using only one hybrid plant that produced flowers. Hybrid plant at the flowering stage was much shorter than Gsu but taller than Sau (Table 1). Hybrid plant had a vegetative shoot below the first flower like Gsu, whereas plants of Lit produced no vegetative shoots. The hybrid had intermediate leaf size between the parents (Table 1; Fig. 2C). Hybrid leaves were sessile and had a tendril at the tip like those of Gsu (Fig. 2C). Number of flowers per plant of the hybrid was similar to Gsu (Table 1). The hybrid produced a slightly smaller number of flowers, which were similar in size to Sau, than both parents (Table 1). Hybrid flowers were pendulous and had an intermediate morphology between the parents, but they were clearly distinguishable from parental flowers (Fig. 3C). Hybrid flowers had a slightly curved style and undulate tepals fused at the base. Some tepals did not expand completely. Flower color of the hybrid was light yellow (JHS 2511), which was slightly different from both parents (Table 1; Fig. 3C). Although the hybrid had partly dehiscent anthers, its pollen grains were shrunken and not stained with acetocarmine (Table 1). The two hybrid plants transplanted to the greenhouse had a diploid number of chromosomes $(2 n=2 x=23)$ (data not shown).

\section{Discussion}

We previously examined broad hybridization among the colchicaceous ornamentals, G. superba, L. modesta, and S. aurantiaca, to widen their variability in horticultural traits, and a number of intra- and intergeneric hybrid plantlets had successfully been obtained 
through ovule culture (Amano et al., 2007; Kuwayama et al., 2005b; Nakamura et al., 2005). Among the intergeneric hybrid plants transplanted to the greenhouse, those of Lit $\times$ Sau, Lit $\times$ Gsu, and Sau $\times$ Gsu have already produced flowers. Although morphology, pollen fertility, and chromosome number of hybrid plants derived from reciprocal crosses between $L$. modesta and $S$. aurantiaca have already been reported (Clark et al., 2005; Eason et al., 2001; Morgan et al., 2001, 2003), this is the first report on the characterization of hybrid plants between Littonia and Gloriosa and between Sandersonia and Gloriosa.

Hybrid plants of Lit $\times$ Sau examined in the present study generally resembled Santonia 'Golden Lights', a hybrid cultivar of $S$. aurantiaca $\times L$. modesta, in plant form and leaf and flower morphologies (Clark et al., 2005; Eason et al., 2001; Morgan et al., 2001, 2003). However, there were small morphological differences between the Lit $\times$ Sau hybrids and Santonia 'Golden Lights'. For example, the Lit $\times$ Sau hybrids produced a smaller number of flowers per plant than Santonia 'Golden Lights'. Flowers of the Lit $\times$ Sau hybrids were entirely vivid orange in color, whereas Santonia 'Golden Lights' often produced reddening flowers. Morgan et al. (2003) and Clark et al. (2005) reported that some morphological characteristics of Santonia 'Golden Lights', including stem length and flower color, were dependent on growing environment, planting season, and tuber size. Therefore, effects of these factors on morphological characteristics of the Lit $x$ Sau hybrids should also be examined in further studies.

The Lit $\times$ Gsu hybrids produced large and bright yellow flowers like Gsu, but they were apparently distinguishable from Gsu by their tepals, which nearly horizontally expanded. Moreover, plants of the Lit $\times$ Gsu hybrids showed a reduced plant height of 80 to 100 $\mathrm{cm}$ compared with parental species under summer conditions in Japan. Thus, these hybrids may be useable directly as a unique cut flower and as a potted plant. Further characterization of the Lit $\times$ Gsu hybrids under various culture conditions as well as propagation of hybrid tubers are necessary.

The Sau $\times$ Gsu hybrid also produced flowers apparently distinguishable from parental flowers. However, these flowers were as small as Sau and tepals of these flowers sometimes did not expand completely. Thus, this hybrid is unsuitable for direct use. However, all three kinds of intergeneric hybrids examined in the present study may be valuable as materials for further breeding of colchicaceous ornamentals. Although all of them showed low or no pollen fertility, artificial chromosome doubling might allow these hybrids to restore fertility. If fertility of the intergeneric hybrids is restored, they can be used as materials for backcross breeding and for producing intergeneric triploid hybrids.

In conclusion, all the three different intergeneric hybrids produced by using three colchicaceous ornamentals, G. superba 'Lutea', L. modesta, and S. aurantiaca, had novel morphological characteristics, some of which were horticulturally attractive. The results obtained in the present study and the previous reports on production and characterization of Santonia 'Golden Lights' indicate the validity of intergeneric hybridization in the improvement programs of colchicaceous ornamentals.

\section{Literature Cited}

Amano, J., S. Kuwayama, Y. Mizuta, T. Oomiya, T. Nakamura, and M. Nakano. 2007. Early identification of intra- and intergeneric hybrids among Colchicaceous ornamentals, Gloriosa spp., Littonia modesta Hook. and Sandersonia aurantiaca Hook., by flow cytometry and random amplified polymorphic DNA analyses. J. Jpn. Soc. Hort. Sci. 76:73-78.

Clark, G.E., G.K. Burge, E.R. Morgan, and C.M Triggs. 2005. Effects of planting date and environment on the cut flower production of Santonia 'Golden Lights'. Acta Hort. 673: 265-271.
Eason, J.R., E.R. Morgan, A.C. Mullan, and G.K. Burge. 2001. Postharvest characteristics of Santonia 'Golden Lights' a new hybrid cut flower from Sandersonia aurantiaca $\times$ Littonia modesta. Postharvest Biol. Technol. 22:93-97.

Fukui, K. 1996. Plant chromosomes at mitosis, p. 1-17. In: K. Fukui and S. Nakayama (eds.). Plant chromosomes: Laboratory methods. CRC Press, Boca Raton, FL.

Japan Horticultural Plant Standard Color Chart. 1984. Japan Color Research Institute, Tokyo.

Kuwayama, S., S. Mori, M. Nakata, T. Godo, and M. Nakano. 2005a. Analyses of anthocyanidins and anthocyanins in flower petals of Lychnis senno and its related species (Caryophyllaceae). Bull. Facul. Agr. Niigata Univ. 58:35-38.

Kuwayama, S., T. Nakamura, Y. Mizuta, T. Oomiya, and M. Nakano. 2005b. Cross-compatibility in interspecific and intergeneric hybridization among the Colchicaceous ornamentals, Gloriosa spp., Littonia modesta and Sandersonia aurantiaca. Acta Hort. 673:421427.

Morgan, E.R., G.K. Burge, J.F. Seelye, M.E. Hopping, J.E. Grant, A.G.F. Warren, and D. Brundell. 2001. Wide crosses in the Colchicaceae: Sandersonia aurantiaca $($ Hook.) $\times$ Littonia modesta (Hook.). Euphytica 121:343-348.

Morgan, E.R., G.K. Burge, J.F. Seelye, A.G.F. Warren, and D.J. Brundell. 2003. 'Santonia Golden Lights': A novel intergeneric hybrid of Sandersonia and Littonia (Colchicaceae). HortScience 38:466-467.

Murashige, T. and F. Skoog. 1962. A revised medium for rapid growth and bioassays with tobacco tissue cultures. Physiol. Plant. 15:473497.

Nakamura, T., S. Kuwayama, S. Tanaka, T. Oomiya, H. Saito, and M. Nakano. 2005. Production of intergeneric hybrid plants between Sandersonia aurantiaca and Gloriosa rothschildiana via ovule culture (Colchicaceae). Euphytica 142:283-289.

Nakano, M. and M. Mii. 1993. Somatic hybridization between Dianthus chinensis and D. barbatus through protoplast fusion. Theor. Appl. Genet. 86:1-5.

Nordenstam, B. 1998. Colchicaceae, p. 175-185. In: K. Kubitzki (ed.). The families and genera of vascular plants. Vol. 3. Springer-Verlag, Berlin.

Vinnersten, A. and G. Reeves. 2003. Phylogenetic relationships within Colchicaceae. Amer. J. Bot. 90:1455-1462. 